Article

\title{
Combining Ability of Quality Protein Maize Inbred Lines for Yield and Morpho-Agronomic Traits under Optimum as Well as Combined Drought and Heat-Stressed Conditions
}

\author{
Nyasha E. Chiuta * ${ }^{(D)}$ and Charles S. Mutengwa \\ Department of Agronomy, Faculty of Science and Agriculture, University of Fort Hare, Private Bag X1314, Alice \\ 5700, Eastern Cape, South Africa; nyashachiuta@gmail.com \\ * Correspondence: cmutengwa@ufh.ac.za; Tel.: +277-2706-2495
}

Received: 20 December 2019; Accepted: 22 January 2020; Published: 28 January 2020

check for updates

\begin{abstract}
Drought and heat stress have perceptibly become major maize (Zea mays L.) yield reducing factors in Sub-Saharan Africa. As such, the objectives of this study were to: (i) determine the type of gene action conditioning tolerance to combined drought and heat stress (CDHS), and (ii) identify inbred lines with good combining ability for yield and other morpho-agronomic traits under CDHS. Twenty-four single cross hybrids (SCHs) obtained from crossing 10 inbred lines in a $4 \times 6$ North Carolina Design II, and a drought-tolerant check, were evaluated under CDHS and optimum conditions in the field. The experiment was laid out in a $5 \times 5$ alpha lattice incomplete block design, replicated three times. Additive gene effects influenced all the traits under CDHS except grain yield, which was influenced by non-additive gene effects. A preponderance of additive genetic effects was observed for all traits recorded under optimum conditions. Inbred lines L30, L6, L5, L17 and L2 showed good combining ability for yield under CDHS, indicating that they could be good parental lines in hybridization programs. Based on the results, SCHs L2*30, L6*13 and L5*18 exhibited high specific combining ability (SCA) effects for yield under CDHS. These hybrids are recommended for further multi-locational evaluation to determine the stability of their performance.
\end{abstract}

Keywords: combining ability; drought; gene effects; heat stress; quality protein maize

\section{Introduction}

Quality protein maize (QPM) has double the amounts of essential amino acids, namely lysine and tryptophan, compared to normal maize [1]. Thus, QPM can be an excellent source of protein in areas where maize is the staple food. Due to its nutritional value, QPM can be added into animal feed where it can be used as a supplementary protein source. Studies by Tiwari et al. [2] observed that broiler chickens fed on QPM increased in weight by approximately $8 \%$ compared to chickens fed on normal maize. Nevertheless, maize cultivars that are good for both human food and fodder purposes have thus far received little attention in breeding programs for tolerance to abiotic stresses [3].

Drought and/or heat stress have perceptibly become major maize yield reducing factors in Sub-Saharan Africa. As such, investing in sustainable mitigation strategies that can reduce yield losses caused by these abiotic stress factors is of paramount importance. Breeding for stress tolerance is one of the economically viable and sustainable ways of reducing yield losses caused by different abiotic stress factors. One of the major tasks of plant breeders is to increase the frequency of desired traits under constrained environments. Combining ability investigations of parental generations need to be conducted under appropriately stressed selection environments for the successful selection of suitable parents that can be used in hybridization programs [4]. 
Combining ability is defined as the capacity of an inbred line to transmit any of its superior traits to its offspring [5]. Successful estimation of combining abilities involves various steps such as parental selection for crossing, performing crosses using a definite mating design, evaluation and interpretation of data. According to Sprague and Tatum [5], combining ability can be divided into general and specific combining ability. General combining ability (GCA) refers to the average performance of a line in different cross combinations. It is mainly influenced by additive gene effects [4]. The term 'additive' means that more than one gene codes for a particular phenotype [4]. Therefore, several genes tend to contribute towards expression of such a phenotypic trait. Additive gene effects are not associated with any form of dominance. Hence, a heterozygous individual always assumes an intermediate phenotype relative to the parents. For example, crossing a tall with a short plant would result in a plant of medium height.

Conversely, specific combining ability (SCA) is defined as those cases where certain hybrid combinations underperform or exceed performance expectations based on the average performance (or GCA) of the parents involved [4]. Simply put, performance of the parental inbred lines has no influence on specific combining ability. Specific combining ability is normally used to select for better performing hybrids and unlike GCA, SCA is influenced by non-additive gene effects [4]. Non-additive gene effects are a result of the interaction between dominance and epistatic gene actions [4]. Sleper and Poehlman [6] postulated that the level of dominance in the offspring can range from partial to over dominance in relation to the mean of its parents. However, total variance within a population is mainly influenced by the genetic variance, environmental variance or the genotype by environment interaction [7].

Several combining ability studies have been conducted under drought-stressed conditions [8-10]. In these studies, others have found additive gene action to be important with regards to grain yield [11] and its components [9], while others found non-additive gene action to be preponderant [12-14]. Results from previous studies revealed that the type of gene action may be dependent upon the genotypes used, as well as the intensity of the stress. On the contrary, combining ability studies under heat-stressed conditions are very scarce [15]. Additionally, most breeding programs in the past were focused on the effects of individual abiotic stresses without considering the effect of these stresses in combination $[16,17]$. Thus, fewer studies have been reported on QPM despite its high nutritional value. As such, the objectives of this study were to determine the gene effects conditioning tolerance to CDHS and to identify inbred lines with good combining ability for yield and other yield components under CDHS, as well as under optimum conditions. Parental inbred lines with enhanced capacity to transmit desirable traits to their progeny can then be selected for use in cultivar development [13].

\section{Materials and Methods}

\subsection{Study Site, Plant Materials, Experimental Set-Up and Management}

The experiment was conducted at the University of Fort Hare Research Farm, Alice, South Africa. The farm is located at $32^{\circ} 46^{\prime} \mathrm{S}$ latitude, $26^{\circ} 50^{\prime} \mathrm{E}$ longitude and is $520 \mathrm{~m}$ above sea level. The area is characterized by a semi-arid climate, with an average annual rainfall of $\pm 525 \mathrm{~mm}$. Temperature, rainfall and evapotranspiration rate data during the critical course of the experiment are represented in Figure 1. 


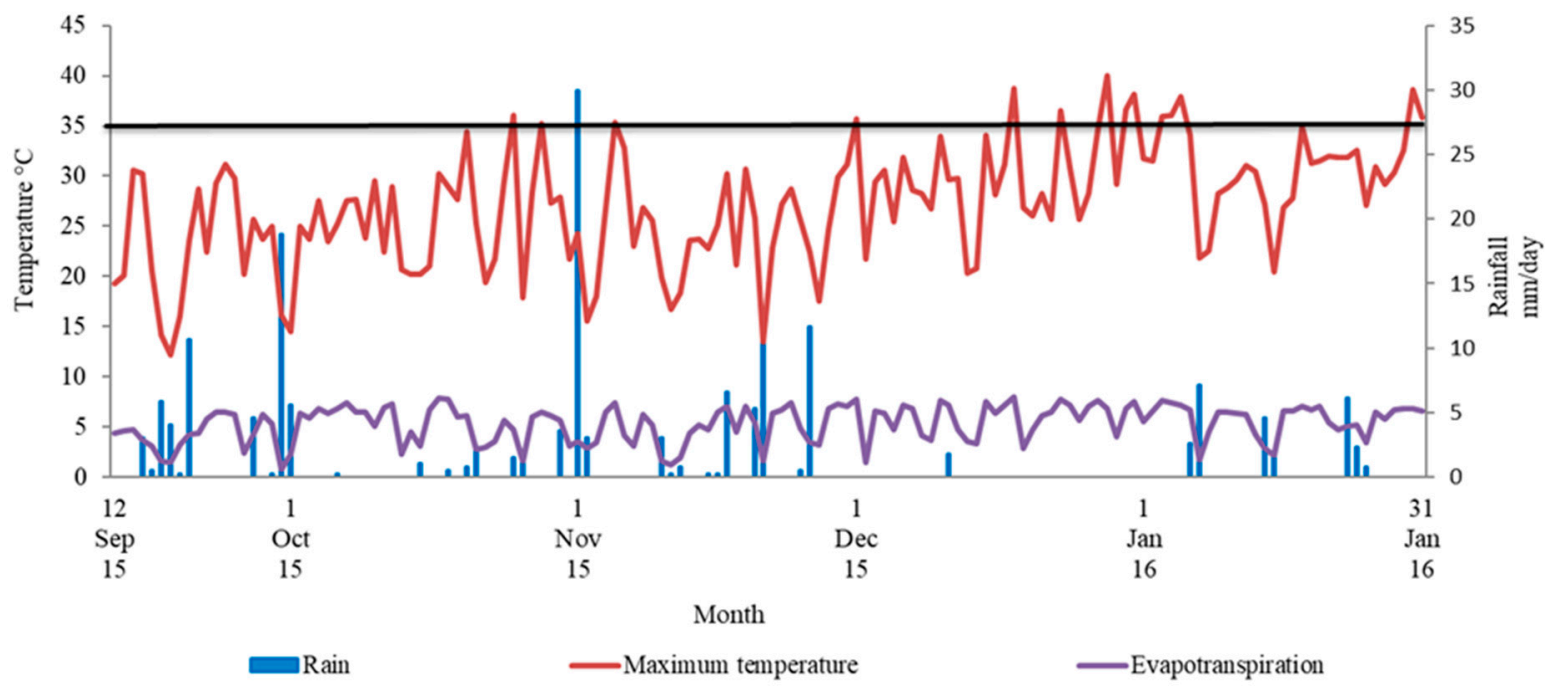

Figure 1. Maximum temperature, rainfall and evapotranspiration from September 2015 to January 2016 at the University of Fort Hare Research Farm, Alice, South Africa.

Quality protein maize inbred lines (Table 1) obtained from Quality Seeds (PTY) LTD, South Africa, were used to generate single cross hybrids (SCHs). A total of 10 inbred lines with enough seeds were crossed using the North Carolina mating Design II (NCD II).

Table 1. Name, origin and drought stress status of the parental lines.

\begin{tabular}{cccc}
\hline Inbred Line & Name & Origin ${ }^{*}$ & ${ }^{*}$ Drought Tolerance Status \\
\hline L2 & D0620Y & M & DT \\
L5 & S0178Y & M & DT \\
L6 & S0249Y & M & DT \\
L13 & R0445Y & F & DS \\
L14 & CM132Y & M & DS \\
L16 & CM321Y & P & DT \\
L17 & EM86Y & B & DS \\
L18 & EM88Y & B & DS \\
L27 & HM46Y & F & DS \\
L30 & HM48Y & L & DS \\
\hline
\end{tabular}

* Inbred lines were obtained from the following sources: M = M37W; P = Potchefstroom; F = F2834T; B = Brazil;

$\mathrm{L}=$ unknown. ${ }^{¥} \mathrm{DT}=$ drought-tolerant at the seedling stage and DS $=$ drought-susceptible at the seedling stage.

Firstly, the inbred lines were divided into two groups (four females and six males) based on their different places of origin. The inbred lines were crossed in a $6 \times 4$ NCD II to produce 24 single cross hybrids (Table 2).

Table 2. List of inbred lines and hybrids produced from crossing the parental lines.

\begin{tabular}{|c|c|c|c|c|}
\hline \multirow{2}{*}{ Inbred Lines } & L2 & L5 & L6 & L14 \\
\hline & \multicolumn{4}{|c|}{ Hybrid } \\
\hline L13 & L2*L13 & L5*L13 & L6*L13 & L14*L13 \\
\hline L16 & L2*L16 & $\mathrm{L}^{*} \mathrm{~L} 16$ & L6*L16 & L14*L16 \\
\hline L17 & L2*L17 & L5*L17 & L6* L17 & L14*L17 \\
\hline L18 & L2*L18 & L5*L18 & L6*L18 & L14*L18 \\
\hline L27 & L2*L27 & $\mathrm{L} 5 * \mathrm{~L} 27$ & L6*L27 & $\mathrm{L} 14^{*} \mathrm{~L} 27$ \\
\hline L30 & $\mathrm{L} 2 * \mathrm{~L} 30$ & L5*L30 & L6*L30 & L14*L30 \\
\hline
\end{tabular}


The production of these $\mathrm{SCH}$ s was done under optimum growing conditions in the field. The $\mathrm{SCH}$ seeds produced were harvested, processed and stored in the cold room at $4{ }^{\circ} \mathrm{C}$ waiting for field evaluation, which was conducted in the following summer season.

The field trial was established on 12 September 2015, so that flowering and grain filling stages could coincide with drought and heat stress. In Alice, the month of December and January are typically associated with little or no rainfall, coupled with very high temperatures. The experiment was laid out as a $5 \times 5$ alpha lattice incomplete block design with three replications, where each replication was a separate experiment. Each plot had four rows, which were $5 \mathrm{~m}$ long with an inter-row spacing of $0.75 \mathrm{~m}$ and intra-row spacing of $0.25 \mathrm{~m}$. The blocks and replicates were separated by $1 \mathrm{~m}$ and $2 \mathrm{~m}$ pathways, respectively. A total of 10 border rows were established on each side of the main experimental plot. Two seeds were manually planted per hill and later thinned to one seedling at the V3 leaf stage [18]. A drought-tolerant, open-pollinated variety (ZM1523) was used as a check for this study [19]. Basal fertilizer [N: P: K ratio 2:3:4 (30)] was applied at a rate of $185 \mathrm{~kg} / \mathrm{ha}$ at planting. Six weeks after crop emergence (WACE), lime ammonium nitrate (LAN) was applied at a rate of $185 \mathrm{~kg} / \mathrm{ha}$. Pre-emergence herbicides Diamant and Sorgomil were applied at the recommended rates of $2.5 \mathrm{l} / \mathrm{ha}$ and 3 l/ha, respectively. Basagran (ai bendioxide $480 \mathrm{~g} / \mathrm{L}$ ) and atrazine $500 \mathrm{SC}$ (ai atrazine $500 \mathrm{~g} / \mathrm{L}$ ), were applied from two WACE to post-anthesis for the control of nutsedge grass and broadleaf weeds at a recommended rate of $2 \mathrm{l} / \mathrm{h}$. Lamadex was used to control cutworm and maize stalk borer at a rate of $70 \mathrm{~mL} / \mathrm{ha}$. A $16 \mathrm{~L}$ Kaufmann knapsack sprayer was used for the application of all agrochemicals.

The plants were exposed to drought stress treatment by withholding irrigation, two weeks before anthesis up to maturity [20]. Flowering of the hybrids occurred between 5 and 19 December. However, two weeks before anthesis, the plants received $12.9 \mathrm{~mm}$ of rainfall. The total relative evapotranspiration rate during that time was $5.71 \mathrm{~mm}$. Flowering and grain filling took place between December 2015 and January 2016. During this period, the plants received sporadic rainfall amounting to $26.93 \mathrm{~mm}$ in total. The total relative evaporation rate during that time was $363.34 \mathrm{~mm}$. The plants were also exposed to random heat stress (temperatures above $35^{\circ} \mathrm{C}$ ) for nine days (Figure 1). As the temperature increased, the rate of evapotranspiration also increased. This resulted in the total evapotranspiration rate being more than the total amount of rainfall received during the drought treatment period.

The longest heat stress period lasted for three consecutive days, while the shortest heat stress period lasted for one day. According to Chen et al. [16], heat stress at flowering and grain filling occurs when plants are exposed to temperatures above $35^{\circ} \mathrm{C}$ for two or more days successively. As such, this trial was considered to have been exposed to mild drought stress in combination with random heat stress. Crops grown under optimum conditions constituted the control plots. The crops received a total of $655 \mathrm{~mm}$ of water throughout the duration of the experiment. Up to physiological maturity, $165.08 \mathrm{~mm}$ of natural rainfall was received, and $490 \mathrm{~mm}$ of water was applied through irrigation.

\subsection{Data Collection and Calculation}

Ten plants from the middle rows of each plot were randomly selected for data collection. The following traits were assessed following procedures described by CIMMYT [21]: canopy temperature $\left({ }^{\circ} \mathrm{C}\right)$, chlorophyll content (spad meter), number of ears per plant, days to $50 \%$ silking, days to $50 \%$ anthesis, anthesis-silking interval (days) was calculated as the difference between days to $50 \%$ silking and days to $50 \%$ anthesis, ear height $(\mathrm{cm})$, cob length $(\mathrm{cm})$, plant height $(\mathrm{cm})$, number of rows per ear and grain yield $(\mathrm{t} / \mathrm{ha})$. Shelled grain weight per plot was measured and adjusted to $12.5 \%$ grain moisture content. A GE Protimeter Grainmaster i-S grain moisture meter (GRN 3000, Rochester, NY, USA) was used to determine grain moisture content. Grain yield per plot was converted to tons/hectare, using the following formula: Grain Yield $=(100-$ moisture content $/ 87.5) \times$ yield/ha.

\subsection{Data Analysis}

The Shapiro-Wilk test was used to test data normality. Subsequently, data for all recorded traits were subjected to analysis of variance (ANOVA) using JMP version 12. The model for NCD II that was 
used for combining ability analysis is as follows: $\mathrm{Y}_{i j k}=\mu+\mathrm{m} i+\mathrm{f} j+(\mathrm{mf}) i j+\mathrm{p} i j k+\mathrm{r} 1+$ eijk. Here, Yijk is the observed progeny of the $i^{\text {th }}$ male crossed with the $j^{\text {th }}$ female in the $k^{\text {th }}$ replication, $\mu$ is the average population mean, $\mathrm{m} i$ is the effect of the general combining ability of the $i$ th mother, $\mathrm{f} j$ is the effect of the $\mathrm{j}^{\text {th }}$ father mated to the $\mathrm{i}^{\text {th }}$ mother (effect of the general combining ability of the $\mathrm{j}^{\text {th }}$ father), mf $i j$ is the interaction effect between the $j^{\text {th }}$ father and the $i^{\text {th }}$ mother (effect of the specific combining ability of the $\mathrm{j}^{\text {th }}$ father and the $\mathrm{i}^{\text {th }}$ mother), $\mathrm{r} 1$ is the effect of the $\mathrm{i}^{\text {th }}$ replication and eijk is the experimental error. As indicated by Hill et al. [22], when calculating the general combining ability of females (GCAf) and males (GCAm) as well as the specific combining ability effects, the formulas used were GCAf $=\mathrm{Xf}-\mu$, GCAm $=X m-\mu$

Here, $\mu$ is the overall mean of crosses, $\mathrm{Xf}$ is the mean of female parents and $\mathrm{Xm}$ is the mean of male parents. Specific combining ability was computed as follows: SCAx $=X x-E(X x)=X x-[G C A f+$ $\mathrm{GCAm}+\mu]$

Here, SCAx is equal to SCA for a cross, $\mathrm{Xx}$ is equal to observed mean values of the cross and $\mathrm{E}(\mathrm{Xx})$ = expected value of the cross based on GCAf and GCAm [22].

\section{Results}

\subsection{Analysis of Variance}

Under CDHS conditions, the mean sum of squares for GCAm was significantly different at $p \leq 0.05$ for all traits except ears per plant, anthesis-silking interval, grain yield and cob length (Table 3). Conversely, the mean squares for GCAf were significantly different at $p \leq 0.05$ for most traits except plant height, ears per plant, chlorophyll content and cob length only. Highly significant effects $(p \leq 0.01)$ were observed for female $\times$ male interaction in all traits except for plant height, ears per plant, number of rows per ear, canopy temperature and cob length. The results obtained showed that the mean sum of squares of GCAm and GCAf combined were higher than SCA mean squares of the hybrids.

Table 3. Mean sum of square effects of general combining ability of males (GCAm), general combining ability of females (GCAf) and specific combining ability (SCA) for yield, yield components and other morpho-agronomic traits under drought and heat-stressed conditions.

\begin{tabular}{|c|c|c|c|c|c|c|c|c|c|c|c|c|}
\hline S.O.V & D.f & EH & PH & EPP & ASI & NRE & DS & GY & CT & $\mathrm{CC}$ & DT & CL \\
\hline GCAf & 3 & $829.31^{* * *}$ & 329.02 & 0.16 & $27.85^{* * *}$ & $2.04 *$ & $62.75^{* * *}$ & $0.13^{*}$ & 14.27 * & 62.51 & $20.38^{* * *}$ & 3.98 \\
\hline GCAm & 5 & $736.15^{* * *}$ & $1849.54^{* * *}$ & 0.11 & 1.22 & $3.16^{* *}$ & $8.88^{* *}$ & 0.08 & $18.35^{* *}$ & $172.40^{* *}$ & $11.69^{* *}$ & 4.13 \\
\hline SCA & 15 & $180.72 * *$ & 236.77 & 0.08 & $10.27 * * *$ & 1.10 & $9.04^{* * *}$ & $0.37^{* * *}$ & 5.92 & $85.61^{* *}$ & $10.15^{* * *}$ & 2.89 \\
\hline
\end{tabular}

Under optimum conditions, the mean sum of squares for GCAm was significantly different for all traits except ears per plant, the number of plants per plot and chlorophyll content (Table 4). Significant GCAf effects were observed for all traits excluding ears per plant and canopy temperature. Significant SCA effects $(p \leq 0.05)$ were observed for most traits except for ears per plant and chlorophyll content.

Table 4. Mean sum of square effects of GCAm, GCAf and SCA for yield, yield components and other morpho-agronomic traits under optimum conditions.

\begin{tabular}{|c|c|c|c|c|c|c|c|c|c|c|c|c|}
\hline S.O.V & D.f & EH & PH & EPP & ASI & NRE & DS & GY & $\mathrm{CT}$ & $\mathrm{CC}$ & DT & CL \\
\hline GCAf & 3 & $1126.70^{* * *}$ & $1021.55^{* * *}$ & 0.19 & $4.20^{* * *}$ & $4.06^{* * *}$ & $34.74^{* * *}$ & $0.66^{* *}$ & 7.37 & $152.72 *$ & $15.31^{* * *}$ & $13.53^{* *}$ \\
\hline GCAm & 5 & $812.06^{* * *}$ & $432.45^{* * *}$ & 0.26 & $1.06^{* *}$ & $4.19 * *$ & $5.79 * * *$ & $0.32 *$ & $10.13 *$ & 98.08 & $4.06^{* * *}$ & $5.17^{* *}$ \\
\hline SCA & 15 & 89.37 & $160.46^{* * *}$ & 0.22 & $2.80 * * *$ & $1.08^{*}$ & $2.80 * * *$ & $0.57^{* * *}$ & 7.89 & 68.37 & $4.34^{* * *}$ & $2.80^{*}$ \\
\hline
\end{tabular}




\subsection{General Combining Ability Analysis}

Estimates of GCA effects for different traits were either negative or positive. Generally, inbred lines having higher and positive GCA values demonstrated good general combining ability characteristics for that trait [23]. However, negative GCA effects were desirable for some traits [24]. Positive GCA effects for yield were desirable. Under CDHS conditions, L30, L6, L5, L17 and L2 exhibited positive GCA effects (Table 5), indicating that these inbred lines were good parental sources of genes for yield. Three of these inbred lines (L2, L5 and L6) were drought-tolerant at the seedling stage, while two of them (L30 and L17) were susceptible to drought at the seedling stage (Table 1). Inbred lines with negative GCA effects (L14, L16, L13, L18 and L27) were described as poor parental sources of genes for yield. All these poor combiners for yield, except L16, were found to be susceptible to drought at the seedling stage.

Table 5. General combining ability effects for yield, yield components and other morpho-agronomic traits under combined drought and heat stress conditions.

\begin{tabular}{ccccccccccc}
\hline Inbred Line & GY & CL & NRE & EPP & CC & DS & DT & ASI & CT & PH \\
\hline GCA & & & & & & & & & & \\
\hline L2 & 0.01 & -0.31 & 0.33 & -0.04 & 1.44 & -2.51 & -0.60 & -1.78 & -0.26 & -2.47 \\
L5 & 0.04 & 0.19 & -0.39 & 0.01 & -2.51 & -0.24 & -0.68 & 0.44 & 0.95 & -2.62 \\
L6 & 0.08 & -0.45 & -0.17 & -0.10 & -0.33 & 1.76 & 1.54 & 0.22 & 0.42 & 6.17 \\
L14 & -0.12 & 0.57 & 0.22 & 0.13 & 1.40 & 0.99 & -0.13 & 1.11 & -1.11 & -1.07 \\
\hline GCA & & & & & & & & & & \\
\hline L13 & -0.03 & 0.62 & -0.44 & -0.10 & 3.22 & -1.01 & -1.29 & 0.28 & -0.85 & -9.81 \\
L16 & -0.10 & 0.11 & 0.31 & -0.01 & 0.43 & -0.10 & -0.46 & 0.36 & 0.82 & -20.08 \\
L17 & 0.04 & -0.47 & 0.14 & -0.01 & 2.19 & -1.01 & -0.71 & -0.31 & 0.60 & 3.79 \\
L18 & -0.05 & -0.72 & 0.81 & 0.07 & -7.36 & 0.99 & 1.38 & -0.39 & 1.43 & 11.17 \\
L27 & -0.01 & 0.72 & -0.94 & 0.15 & 0.01 & 0.65 & 0.46 & 0.19 & -1.96 & 10.67 \\
L30 & 0.14 & -0.26 & 0.14 & -0.10 & 1.51 & 0.49 & 0.63 & -0.14 & -0.04 & 4.26 \\
\hline
\end{tabular}

$\mathrm{GY}=$ grain yield, $\mathrm{CL}=$ cob length, $\mathrm{NRE}=$ number of rows per ear, $\mathrm{EPP}=$ ears per plant, $\mathrm{CC}=$ chlorophyll content, $\mathrm{DS}=$ days to $50 \%$ silking, $\mathrm{DT}=$ days to $50 \%$ anthesis, $\mathrm{ASI}=$ anthesis-silking interval, $\mathrm{CT}=$ canopy temperature, $\mathrm{PH}$ = plant height, $\mathrm{GCA}_{\mathrm{f}}=$ general combining ability (female) and $\mathrm{GCA}_{\mathrm{m}}=$ general combining ability (male).

Positive GCA effects for cob length were also desirable. Inbred lines L5, L14, L13, L16 and L27 were the only inbred lines that combined well for this trait. The rest of the inbred lines were poor combiners. The worst combiner for cob length was L18. Estimates of GCA for the number of rows per ear were both positive and negative. Positive GCA effects implied the presence of many rows per ear, which could be translated into more yield for the respective genotype. Inbred lines L18, L2, L14, L16 and L30 had positive GCA effects and were described as good parental sources of genes for the number of rows per ear. The rest of the inbred lines were poor sources of genes for increased number of rows per ear. Positive GCA effects for the number of ears per plant were desirable. Inbred lines L5, L14, L18 and L27 were generally good combiners whereas L2, L16, L6, L13, L17 and L30 were poor combiners for the number of ears per plant. Under CDHS conditions, positive GCA effect values of chlorophyll content were desirable. Positive GCA depicted the plant's ability to maintain chlorophyll content, which would enable such plants to photosynthesize when others were senescing. Inbred lines L2, L13, L16, L17, L30, L14 and L27 were good combiners for chlorophyll content. However, L6, L5 and L18 did not combine well for this trait.

Negative GCA effects were desirable for days to $50 \%$ anthesis and silking since it demonstrated the ability of the plant to flower early under stressed conditions. According to Shavrukov et al. [25], plants that flower early show a mannerism of drought and/or heat stress evasion. Inbred lines L2, L5, L13, L16 and L17 had negative GCA effects for both days to 50\% anthesis and days to 50\% silking. Inbred line L14 had negative GCA effects for days to $50 \%$ anthesis only. The other inbred lines showed positive GCA values implicating that they were late maturing genotypes. Late maturing genotypes are not desirable since yield is greatly reduced under stressed conditions. Negative GCA values for the 
anthesis-silking interval were desirable since it implied good synchronization of male (tasseling) and female (silking) flowering. Inbred lines L2, L17, L18 and L30 recorded negative GCA effect values thus making them desirable sources of genes for shortening the anthesis-silking interval in breeding programs. Inbred lines L5, L6, L13, L14, L16 and L27 recorded positive GCA effects, indicating that these inbred lines were poor parental sources of genes controlling flowering. Negative GCA effects for canopy temperature and plant height were desirable under CDHS conditions. Negative GCA effects for canopy temperature implied that canopy temperature was not elevated under CDHS conditions. Inbred lines L2, L13, L14, L30 and L27 were good combiners for canopy temperature while L6, L16, L17, L5 and L18 were poor combiners. Plants showing negative GCA effects for plant height implied that the plants were short. The development of short plants is desirable since such plants are not prone to logging unlike tall plants [24]. Short plants, as shown by negative GCA effect values, were therefore desirable. Inbred lines L2, L5, L14, L13 and L16 were generally good parental sources of genes for plant height whereas L18, L27, L30, L17 and L6 were poor parental sources.

Under optimum conditions, inbred lines L2, L5, L14, L16, L17 and L30 combined well for grain yield while L6, L13, L18 and L27 were poor combiners (Table 6). All inbred lines except L2, L18 and L27 were good combiners for cob length. Inbred lines L2, L14, L17 and L18 were the only good combiners for number of rows per ear. Approximately $50 \%$ of the inbred lines showed positive GCA effects for ears per plant under optimum conditions. Inbred lines L5, L14, L16, L17 and L18 were generally good combiners for ears per plant while L2, L6, L13, L27 and L30 were poor combiners. Combining ability effects for the rest of the traits under optimum conditions are shown in Table 6.

Table 6. General combining ability effects for yield, yield components and other morpho-agronomic traits under optimum conditions.

\begin{tabular}{ccccccccccc}
\hline Inbred Line & GY & CL & NRE & EPP & CC & DS & DT & ASI & CT & PH \\
\hline GCAf & & & & & & & & & & \\
\hline L2 & 0.14 & -1.24 & 0.58 & -0.06 & 1.98 & -1.94 & -1.25 & -0.69 & -0.46 & -9.39 \\
L5 & 0.04 & 0.75 & -0.53 & 0.11 & -4.10 & -0.06 & -0.14 & 0.08 & -0.42 & 3.71 \\
L6 & -0.28 & 0.11 & -0.19 & -0.11 & 1.83 & 0.94 & 0.75 & 0.19 & 0.68 & 7.95 \\
L14 & 0.10 & 0.42 & 0.14 & 0.06 & 0.29 & 1.06 & 0.64 & 0.42 & -0.04 & -2.26 \\
\hline GCAm & & & & & & & & & & \\
\hline L13 & -0.29 & 0.05 & -0.31 & -0.06 & 3.40 & -1.06 & -0.78 & -0.28 & 1.30 & -8.07 \\
L16 & 0.20 & 0.34 & -0.06 & 0.03 & -1.97 & -0.47 & -0.44 & -0.03 & -0.60 & -1.16 \\
L17 & 0.09 & 0.16 & 0.11 & 0.28 & 2.60 & -0.14 & -0.03 & -0.11 & 0.59 & -0.05 \\
L18 & -0.02 & -0.79 & 1.11 & 0.47 & -2.10 & 0.78 & 0.31 & 0.47 & 0.29 & 1.14 \\
L27 & -0.01 & -0.23 & -0.31 & -0.14 & -1.21 & 0.61 & 0.89 & -0.28 & -1.28 & 10.36 \\
L30 & 0.80 & 0.95 & -0.56 & -0.06 & -0.73 & 0.28 & 0.06 & 0.22 & -0.30 & -2.22 \\
\hline
\end{tabular}

$\mathrm{GY}=$ grain yield, $\mathrm{CL}=$ cob length, $\mathrm{NRE}=$ number of rows per ear, $\mathrm{EPP}=$ ears per plant, $\mathrm{CC}=$ chlorophyll content, $\mathrm{DS}=$ days to $50 \%$ silking, $\mathrm{DT}=$ days to $50 \%$ anthesis, $\mathrm{ASI}=$ anthesis-silking interval, $\mathrm{CT}=$ canopy temperature, $\mathrm{PH}$ = plant height, $\mathrm{GCA}_{\mathrm{f}}=$ general combining ability (female) and $\mathrm{GCA}_{\mathrm{m}}=$ general combining ability (male).

Based on the results obtained, different inbred lines combined well for different traits under CDHS and optimum conditions. None of the inbred lines tested generally combined well for all the traits measured across environments. However, L2 was a good parental source of genes for most traits, except for cob length and ears per plant under CDHS, and under optimum conditions. This inbred line was previously observed to have drought tolerance at the seedling stage (Table 1).

\subsection{Specific Combining Ability Analysis}

Significant SCA effects $(p \leq 0.05)$ were observed for most of the traits under CDHS, and under optimum conditions. Under CDHS, no significant effects were observed for canopy temperature, cob length, plant height and the number of ears per plant. Under optimum conditions, no significant effects were observed for grain yield, cob length, canopy temperature and the number of ears per plant. Negative and positive SCA effect values were recorded under CDHS, and under optimum conditions. 
Depending on the trait, cross combinations with high positive SCA values were denoted as best specific combiners for that trait while those with negative SCA effects were described as poor combiners and vice-versa. Positive SCA effect values for grain yield, cob length, the number of rows per ear, ears per plant and chlorophyll content were desirable. As such, SCHs exhibiting high positive SCA values for these traits were considered as good specific combiners while those exhibiting negative SCA values were regarded as poor combiners.

Under CDHS, 50\% of the hybrids combined well for grain yield. Cross combinations L5*L18 (0.36), L14*L13 (0.35), L6*L13 (0.34) and L2*L30 (0.33) combined well for grain yield (Table 7), recording total grain yields of $3.90,3.53,4.00$ and $4.25 \mathrm{t} / \mathrm{ha}$, respectively (Table 8 ). These hybrids performed better than or approximately similar to the drought-tolerant check ZM 1523 (3.57t/ha). Three of these SCHs (L5*L18; L6* L13 and L2*L30) were generated from crosses between genotypes that were drought-tolerant and drought-susceptible at the seedling stage (Table 1). The remaining SCH (L14*L13) was generated from a cross between two genotypes that were susceptible to drought stress at the seedling stage (Table 1). Single cross hybrid L6* L16 (-0.54) with grain yield of $1.46 \mathrm{t} /$ ha was the worst specific combiner for grain yield under stressed conditions. It was notable that this $\mathrm{SCH}$ was generated from a cross between genotypes classified as being drought-tolerant at the seedling stage (Table 1). Percentage losses in grain yield of hybrids subjected to CDHS relative to optimum conditions ranged from $10.7 \%$ (L5* L18) to $70.7 \%$ (L14*L17). The average yield loss for all the 24 SCHs was $50,4 \%$ (data not shown).

Table 7. Specific combining ability effects for yield, yield components and other morpho-agronomic traits under combined drought and heat-stressed (CDHS) conditions.

\begin{tabular}{ccccccccccc}
\hline Hybrid & GY & CL & NRE & EPP & CC & DS & DT & ASI & CT & PH \\
\hline L2*L13 & -0.37 & 0.10 & -2.17 & 0.04 & -3.87 & 0.51 & -0.24 & 0.61 & -0.69 & 10.54 \\
L2*L16 & 0.00 & 0.00 & 0.67 & -0.04 & -3.04 & 2.60 & 1.60 & 0.86 & -1.15 & -1.25 \\
L2*L17 & 0.28 & -0.10 & 1.00 & 0.29 & 1.52 & 0.18 & -1.15 & 1.19 & 0.50 & -5.96 \\
L2*L18 & -0.17 & -1.20 & -1.08 & -0.13 & 4.63 & -2.49 & 1.76 & -4.39 & -0.93 & -13.05 \\
L2* L27 & -0.06 & 0.38 & -0.42 & -0.21 & 1.64 & 1.51 & 0.68 & 0.69 & 0.26 & 5.00 \\
L2*L30 & 0.33 & 0.82 & 2.00 & 0.04 & -0.88 & -2.32 & -3.49 & 1.03 & 2.01 & 4.71 \\
L5*L13 & -0.32 & -0.41 & -0.50 & -0.01 & 3.29 & 0.90 & -0.15 & 1.06 & 0.73 & -7.39 \\
L5*L16 & 0.29 & 1.66 & 0.67 & -0.10 & 4.24 & -1.68 & 0.01 & -1.69 & 2.16 & 1.73 \\
L5*L17 & 0.09 & 0.00 & 0.33 & -0.10 & 1.07 & 0.90 & 1.93 & -1.03 & -0.42 & 11.11 \\
L5*L18 & 0.36 & -0.74 & 2.25 & 0.15 & -14.83 & -0.10 & -0.15 & 0.06 & 0.39 & 12.33 \\
L5*L27 & -0.19 & -0.39 & -1.42 & 0.07 & 4.83 & -1.76 & -2.24 & 0.47 & -1.45 & -7.57 \\
L5* L30 & -0.17 & -0.13 & -1.33 & -0.01 & 1.40 & 1.74 & 0.60 & 1.14 & -1.41 & -10.21 \\
L6*L13 & 0.34 & -0.27 & -0.50 & 0.10 & 2.30 & -0.10 & 0.29 & -0.39 & -0.37 & 2.96 \\
L6*L16 & -0.54 & -1.71 & 0.33 & 0.01 & -1.86 & -0.01 & -0.21 & 0.19 & -0.93 & 3.87 \\
L6*L17 & 0.04 & 0.02 & 1.33 & 0.01 & -0.77 & -1.76 & -2.29 & 0.53 & 0.88 & -6.69 \\
L6*L18 & -0.31 & 2.13 & -2.42 & -0.07 & 5.91 & 1.24 & 0.63 & 0.61 & -1.51 & -6.83 \\
L6*L27 & 0.26 & -0.19 & 0.58 & -0.15 & -2.99 & -0.76 & -0.13 & -0.64 & 1.58 & -1.48 \\
L6*L30 & 0.22 & 0.01 & 0.67 & 0.10 & -2.58 & 1.40 & 1.71 & -0.31 & 0.36 & 8.18 \\
L14*L13 & 0.35 & 0.58 & 3.17 & -0.13 & -1.72 & -1.32 & -0.04 & -1.28 & 0.32 & -6.11 \\
L14*L16 & 0.25 & 0.05 & -1.67 & 0.13 & 0.66 & -0.90 & -1.54 & 0.64 & -0.07 & -4.35 \\
L14*L17 & -0.40 & 0.07 & -2.67 & -0.21 & -1.82 & 0.68 & 1.38 & -0.69 & -0.96 & 1.54 \\
L14*L18 & 0.12 & -0.19 & 1.25 & 0.04 & 4.30 & 1.35 & -2.38 & 3.72 & 2.05 & 7.55 \\
L14*L27 & -0.01 & 0.20 & 1.25 & 0.29 & -3.47 & 1.01 & 1.54 & -0.53 & -0.39 & 4.05 \\
L14*L30 & -0.31 & -0.71 & -1.33 & -0.13 & 2.06 & -0.82 & 1.04 & -1.86 & -0.95 & -2.69 \\
\hline
\end{tabular}

$\mathrm{GY}=$ grain yield, $\mathrm{CL}=$ cob length, $\mathrm{NRE}=$ number of rows per ear, $\mathrm{EPP}=$ ears per plant, $\mathrm{CC}=$ chlorophyll content, $\mathrm{DS}=$ days to $50 \%$ silking, $\mathrm{DT}=$ days to $50 \%$ anthesis, $\mathrm{ASI}=$ anthesis-silking interval, $\mathrm{CT}=$ canopy temperature and $\mathrm{PH}=$ plant height.

Approximately $54 \%$ of the SCHs had positive SCA effects for the number of rows per ear. Hybrids L14*L13 (3.17), L5*L18 (2.25) and L2*L30 (2.00) were the best cross combinations for this trait while L14*L17 (-2.67), with the highest negative SCA value, was the worst cross combination. With regards to chlorophyll content, SCHs L6*L18 (5.91), L5*L27 (4.83), L2*L18 (4.63) and L14*L18 (4.30) recorded the highest positive SCA effect values and these cross combinations were good combiners for chlorophyll 
content. In contrast, $\mathrm{L} 5^{*} \mathrm{~L} 18(-14.83)$ was the worst cross combination for this trait. Negative SCA effects for anthesis-silking interval and days to $50 \%$ silking and anthesis were desired. Negative SCA effects for anthesis-silking interval demonstrated that flowering synchronization was good while negative days to $50 \%$ silking and anthesis demonstrated early flowering of the SCHs. Single cross hybrids L2* ${ }^{*} 18(-2.49), \mathrm{L} 2^{*} \mathrm{~L} 30(-2.32), \mathrm{L} 5^{*} \mathrm{~L} 27$ and L6* $\mathrm{L} 17(-1.76)$ were the top five early flowering cross combinations with regards to days to $50 \%$ silking. Single cross hybrid L2*L16 (2.60) was the worst cross combination for days to $50 \%$ silking. Single cross hybrids L2* ${ }^{*} 30(-3.49)$, L14*L18 $(-2.38)$ and L6* L17 (-2.29) were the top three early flowering cross combinations while SCH L5*L17 (1.93) was the worst combiner with regards to days to $50 \%$ anthesis. Only $42 \%$ of the SCHs were good combiners for anthesis-silking interval under CDHS conditions. The top three best cross combinations for anthesis-silking interval were L2*L18 $(-4.39), \mathrm{L} 14^{*} \mathrm{~L} 30(-1.86)$ and L5* L16 $(-1.69)$, while SCHs L14* L18 (3.72), L2*L17 (1.19) and L5* L30 (1.14) were considered as the three worst combiners.

Table 8. Best and worst cross combinations for grain yield under combined drought and heat stress conditions.

\begin{tabular}{cccc}
\hline \multicolumn{2}{c}{ High-Yielding Hybrids } & \multicolumn{2}{c}{ Low-Yielding Hybrids } \\
\hline Hybrid & Grain Yield (t/ha) & Hybrid & Grain Yield (t/ha) \\
\hline L2*L30 & 4.25 & L6*L16 & 1.45 \\
L6*L30 & 4.13 & L14*L17 & 1.67 \\
L6*L13 & 4.00 & L2*L13 & 1.94 \\
L5*L18 & 3.90 & L5*L13 & 2.16 \\
L6*L27 & 3.85 & L14*L30 & 2.20 \\
ZM1523 & 3.57 & - & - \\
\hline
\end{tabular}

Under optimum conditions, the best cross combinations for the number of rows per ear were SCHs L2*L27 (1.08), L5*L16 (0.61) and L6*L13 (0.53). Single cross hybrids L2*L18 (6.57), L5*L16 (6.20) and L14*L18 (4.32) combined well for chlorophyll content (Table 9). On the other hand, SCHs L5*L13 $(-0.81), \mathrm{L} 2 * \mathrm{~L} 17(-0.67), \mathrm{L} 2 * \mathrm{~L} 18(-0.67)$ and $\mathrm{L} 5 * \mathrm{~L} 30(-0.56)$ were the worst three combinations for number of rows per ear whereas L5*L18 (-13.03), L2*L16 (-4.96) and L6*L16 $(-2.17)$ were the worst three combiners for chlorophyll content.

With regards to days to 50\% silking, SCHs L6*L16 (-1.53), L2*L18 (-0.89) and L14*L18 (-0.89) were the best top three combiners while L14* 27 (1.61), L6*1 1 8 (1.56) and L2* ${ }^{*} 17$ (1.03) were the worst combiners. Approximately $50 \%$ of the SCHs combined well for days to $50 \%$ anthesis. The top three best combiners for days to $50 \%$ anthesis were SCHs L5* ${ }^{*} 27(-1.78), \mathrm{L}^{*} 4^{*} \mathrm{~L} 16(-1.22)$ and L14*L18 $(-0.97)$ whereas L14*L27 (2.44), L5*L16 (1.56) and L5*L18 (1.47) were the bottom three worst combiners. Single cross hybrids L5*L18 $(-1.25), \mathrm{L} 6{ }^{*} \mathrm{~L} 16(-0.86)$ and L14* $27(-0.83)$ were the top three best combiners for anthesis-silking interval while L6*L18 (1.64), L14*L16 (1.58) and L5* L27 (1.17) were the bottom three worst combiners. Based on the results obtained, no cross combination performed well for all traits recorded across environments. However, hybrid $\mathrm{L}^{*} 13$ was a good combiner for grain yield across the environments whereas, L2*18 and L14*18 combined well for chlorophyll content across environments. 
Table 9. Specific combining ability effects for yield, yield components and other morpho-agronomic traits under optimum conditions.

\begin{tabular}{ccccccccccc}
\hline Hybrid & GY & CL & NRE & EPP & CC & DS & DT & ASI & CT & PH \\
\hline L2*L13 & -0.36 & -0.30 & 0.08 & -0.11 & 2.68 & 0.28 & 0.67 & -0.39 & 0.96 & 5.11 \\
L2*L16 & -0.03 & 0.26 & -0.17 & 0.14 & -4.96 & 0.36 & 0.33 & 0.03 & -0.54 & -3.96 \\
L2*L17 & 0.34 & 0.35 & -0.67 & 0.22 & -0.19 & 1.03 & 0.25 & 0.78 & -0.80 & -3.92 \\
L2*L18 & 0.43 & 0.32 & -0.67 & -0.64 & 6.57 & -0.89 & -0.42 & -0.47 & 1.03 & -7.76 \\
L2* L27 & -0.43 & -0.02 & 1.08 & -0.03 & -2.01 & -0.39 & -0.67 & 0.28 & -3.09 & 6.62 \\
L2*L30 & -0.71 & -1.08 & 0.33 & -0.11 & -2.09 & -0.39 & -0.17 & -0.22 & 2.46 & 3.91 \\
L5*L13 & -0.16 & -1.05 & -0.81 & -0.28 & -0.48 & 0.06 & -0.44 & 0.50 & 0.32 & -1.34 \\
L5*L16 & 0.51 & -0.63 & 0.61 & 0.31 & 6.24 & 0.81 & 1.56 & -0.75 & -0.61 & -1.76 \\
L5*L17 & 0.31 & 1.62 & 0.44 & 0.06 & 4.00 & -0.53 & 0.14 & -0.67 & -0.87 & 11.48 \\
L5*L18 & -0.67 & 0.07 & 0.44 & -0.14 & -13.03 & 0.22 & 1.47 & -1.25 & -0.70 & 5.29 \\
L5* L27 & 0.31 & -1.23 & -0.14 & -0.19 & 1.89 & -0.61 & -1.78 & 1.17 & 2.77 & -10.28 \\
L5* L30 & -1.07 & 0.76 & -0.56 & -0.28 & 1.38 & 0.06 & -0.94 & 1.00 & -0.91 & -3.39 \\
L6*L13 & 0.58 & 1.62 & 0.53 & 0.28 & 1.61 & 0.39 & 0.67 & -0.28 & -1.81 & -0.09 \\
L6*L16 & -0.35 & -0.71 & -0.39 & -0.14 & -2.17 & -1.53 & -0.67 & -0.86 & 1.06 & -4.50 \\
L6*L17 & -0.32 & -0.81 & 0.11 & -0.39 & -0.89 & -0.53 & -0.75 & 0.22 & 0.77 & 0.04 \\
L6*L18 & -0.27 & 0.04 & 0.44 & -0.58 & 2.81 & 1.56 & -0.08 & 1.64 & 0.10 & 7.70 \\
L6*L27 & -0.01 & -0.74 & -0.47 & 0.03 & -0.01 & -0.61 & 0.00 & -0.61 & 0.98 & -3.37 \\
L6*L30 & -0.39 & 0.13 & -0.22 & 0.28 & -1.35 & 0.72 & 0.83 & -0.11 & 0.36 & 0.21 \\
L14*L13 & -0.06 & -0.32 & 0.19 & 0.11 & -0.43 & -0.72 & -0.89 & 0.17 & 0.77 & -3.68 \\
L14*L16 & -0.13 & 1.03 & -0.06 & -0.31 & -0.19 & 0.36 & -1.22 & 1.58 & 0.34 & 10.21 \\
L14*L17 & -0.34 & -1.20 & 0.11 & 0.11 & 0.62 & 0.03 & 0.36 & -0.33 & 1.15 & -7.60 \\
L14*L18 & 0.51 & -0.47 & -0.22 & -0.75 & 4.32 & -0.89 & -0.97 & 0.08 & -0.19 & -5.24 \\
L14*L27 & 0.13 & 0.07 & -0.47 & 0.19 & 0.14 & 1.61 & 2.44 & -0.83 & -0.41 & 7.04 \\
L14*L30 & -0.87 & 0.14 & 0.44 & 0.11 & 1.31 & -0.39 & 0.28 & -0.67 & -1.66 & -0.73 \\
\hline
\end{tabular}

$\mathrm{GY}=$ grain yield, $\mathrm{CL}=$ cob length $\mathrm{NRE}=$ number of rows per ear, $\mathrm{EPP}=$ ears per plant, $\mathrm{CC}=$ chlorophyll content, $\mathrm{DS}=$ days to $50 \%$ silking, $\mathrm{DT}=$ days to $50 \%$ anthesis, $\mathrm{ASI}=$ anthesis-silking interval, $\mathrm{CT}=$ canopy temperature and $\mathrm{PH}=$ plant height.

\subsection{Relative Magnitudes of General and Specific Combining Ability Effects}

The GCA:SCA mean square ratios for different traits were computed (Table 10). The highest GCA:SCA ratios under CDHS conditions were recorded for plant height (9:1) and days to $50 \%$ silking (8:1). General combining ability was three times more than SCA for traits such as chlorophyll content, days to $50 \%$ anthesis, anthesis-silking interval, cob length and ears per plant. This showed that GCA effects were more important than SCA effects in influencing these traits under CDHS. The GCA:SCA ratio for grain yield was less than one and slightly above 0.5 . This indicated that SCA was approximately twice more important than GCA for determination of grain yield under CDHS conditions. The GCA and SCA ratios therefore showed that additive genetic effects influenced all traits measured under CDHS except for grain yield.

Table 10. Ratios of GCA:SCA mean squares for yield, yield components and other morpho-agronomic traits under optimum as well as combined drought and heat-stressed conditions.

\begin{tabular}{ccccccccccc}
\hline & GY & CL & NRE & EPP & CC & DS & DT & ASI & CT & PH \\
\hline Drought and Heat stress & 0.57 & 2.81 & 4.73 & 3.38 & 2.74 & 7.92 & 3.16 & 2.83 & 5.51 & 9.2 \\
Optimum & 1.72 & 6.68 & 7.64 & 2.05 & 3.67 & 14.48 & 4.46 & 1.88 & 2.22 & 9.06 \\
\hline
\end{tabular}

$\mathrm{GY}=$ grain yield, $\mathrm{CL}=$ cob length, $\mathrm{NRE}=$ number of rows per ear, $\mathrm{EPP}=$ ears per plant, $\mathrm{CC}=$ chlorophyll content, $\mathrm{DS}=$ days to $50 \%$ silking, $\mathrm{DT}=$ days to $50 \%$ anthesis, $\mathrm{ASI}=$ anthesis-silking interval, $\mathrm{CT}=$ canopy temperature and $\mathrm{PH}=$ plant height.

On the other hand, the GCA:SCA ratios for all traits measured under optimum conditions were greater than one. The highest GCA:SCA ratio was recorded for days to $50 \%$ silking (14:1), while the lowest GCA:SCA ratio of 2:1 was recorded for traits such as anthesis-silking interval, grain yield, 
canopy temperature and ears per plant. Thus, all traits were significantly influenced by additive genetic effects under optimum conditions.

\section{Discussion}

The success of most crop improvement programs heavily depends upon the capacity of the genetic material to convey desired traits unto its progeny. As such, genetic materials used within the breeding program should undergo critical selection procedures to determine their inherent potentials. Combining ability studies involve determining the average breeding value (GCA) of germplasm used as well as the genetic value due to the interaction between these specific genes in a cross combination (SCA). The latter is due to non-additive or dominant gene effects while the former is due to the additive effects of genes. Variances due to SCA and GCA were estimated for assessing the gene action influencing inheritance of different characteristics studied under CDHS and under optimum conditions. Results showed significant differences for GCA and SCA effects thus implying the presence of adequate additive variation and dominance variance, respectively. The GCA:SCA ratios were used to identify gene effects that were more important in controlling the estimates of each trait. Under CDHS, GCA effects were more important in determining most traits except for grain yield since additive variances were higher than non-additive variances. According to Abbas et al. [26], preponderance of additive effects is observed when the GCA:SCA ratio is greater than one while preponderance of dominance effects is observed when the ratio is less than one.

Dominance or epistatic genetic effects mostly influenced maize grain yield under CDHS. Similar observations were reported by Abdel-Moneam et al. [27] and Njeri et al. [28] working on drought-stressed maize. Akbar et al. [29] and Naveed et al. [15] also reported that non-additive genetic effects were responsible for grain yield inheritance under heat-stressed conditions. Pfunde [30] observed that inheritance of grain yield among white QPM inbred lines was mostly influenced by non-additive gene action under CDHS. Since SCA effects were predominant in determining yield under CDHS, the breeding strategy to improve this trait under these stresses must consist of inbreeding followed by cross-breeding to generate superior hybrids [31]. However, it is imperative to note that information concerning genetic effects governing maize grain yield and other traits under CDHS is still scarce to the best of our knowledge. Nevertheless, under optimum conditions, additive genetic effects influenced all characteristics that were studied, including grain yield. Makumbi [32] also reported the preponderance of additive genetic effects on maize grain yield under optimum conditions. Generally, results from this study showed that gene action governing grain yield under CDHS was different from that controlling grain yield under optimum conditions. This emphasizes the need for stress breeding for the improvement of maize yields under semi-arid regions. Since emphasis has previously been on individual stresses, it is now more important to assess the performance of genotypes under combinations of stresses that are typically experienced in areas where the germplasm is targeted to be used.

According to the GCA values obtained in this study, inbred lines L30, L6, L5, L17 and L2 were observed as good general combiners for grain yield under CDHS since they exhibited high GCA values. Three of these inbred lines (L6, L5 and L2) were tolerant while the remaining two (L30 and L17) were susceptible to drought at the seedling stage. This may suggest that drought tolerance at the seedling stage was not synonymous with tolerance to CDHS during vegetative and later stages of growth in this study. This could be further supported by the fact that the lowest yielding SCH ( $\left.6^{*} \mathrm{~L} 16\right)$ was derived from a cross between two inbred lines that were classified to be drought-tolerant at the seedling stage. Most of these inbred lines were able to transfer their high yielding potential to their SCHs. The highest yielding SCH (L2* L30: $4.24 \mathrm{t} / \mathrm{ha}$ ) came from two lines that were generally good combiners for yield under CDHS. However, in some cases, high yield was observed in cross combinations involving one line with low GCA for that particular trait under stressed conditions. For example, SCH L5*L18 produced good yields of $3.90 \mathrm{t} / \mathrm{ha}$ under CDHS although L18 had a negative GCA value for grain yield under CDHS. Similar observations were reported by Kaya and Atakisi [33] and Ejigu et al. [24]. In their 
studies, high SCA values for grain yield were obtained from cross combinations between a line with low GCA and a line with high GCA value for yield. Additionally, Njeri et al. [28] also observed that one parent of the high-yielding hybrid had a low GCA value for grain yield under drought-stressed conditions. Such observations demonstrate the importance of non-additive gene effects in influencing yield potential.

In this study, the high yields from SCHs involving a genotype with a low GCA might partly be explained by the complementarity of different heterotic groups (HGs) involved in the crosses. For example, SCH L6* ${ }^{*} 13$ produced the second highest yield, and yet inbred line L13 had a negative GCA for yield. Based on their pedigrees, L6 belongs to heterotic group (HG) M, while L13 belongs to HG F. Heterotic group M consists of the outstanding breeding source M37W, and was generated from the crossing of an Australian inbred line called 21A, and a US OPV called ellicorse. Heterotic group F was sourced from a local South African yellow OPV called Teko Yellow. One of the superior and recommended heterotic patterns in South African maize breeding involves crossing HGs F and M [34]. Other recommended heterotic uses for some maize germplasm that were used in this study were summarized by Gevers [33] and could explain some of the observed performances of various SCHs.

\section{Conclusions}

Based on the results, grain yield was significantly influenced by non-additive gene action under CDHS. The breeding strategy to improve yield under CDHS must consist of inbreeding followed by cross-breeding to generate superior hybrids. Single cross hybrids L2*L30, L6*L13, L14*L13 and L5*L18 exhibited high SCA effects for grain yield under the stressed environment. These hybrids were therefore the highest yielders under CDHS. As such, these hybrids can be recommended for further evaluation, such as in intermediate variety trials. They can also be used as parents when generating three-way and four-way hybrids in breeding programs. On the other hand, inbred lines L17, L30, L2, L5 and L6 exhibited high GCA effects for grain yield under CDHS and thus can be very useful source materials in hybridization programs.

Author Contributions: N.E.C. contributed with designing the experiment, data collection, data analysis and interpretation, writing, editing and review of the first and final drafts. C.S.M. contributed through acquisition of funding for the project, supervision, reviewing, writing and editing of the first and final drafts. All authors have read and agreed to the published version of the manuscript.

Funding: The Govan Mbeki Research and Development Centre (GMRDC) of the University of Fort Hare and the National Research Foundation (NRF), S\&F-Innovation Scholarship (reference: SFH14073183584, grant no. 94743), and the Research and Technology Fund (grant no. 98706) are acknowledged for funding the project.

Acknowledgments: Quality Seed (PTY) LTD is acknowledged for supplying germplasm that was used for the study.

Conflicts of Interest: The authors declare no conflicts of interest.

\section{References}

1. Prasanna, B.M.; Vasal, S.K.; Kassahun, B.; Singh, N.N. Quality Protein Maize. Curr. Sci. 2001, 81, $1308-1319$.

2. Tiwari, M.R.; Neopane, D.; Paudel, T.P.; Singh, U.M. Evaluation of Quality Protein Maize (QPM) and Normal Maize for Growth Performance of Broiler Chicken in Nepal. GJSFR Agri. Vet. 2013, 13, 35-49.

3. Ahsan, M.; Hussain, M.M.; Farooq, A.; Khaliq, I.; Farooq, J.; Ali, Q.; Kashif, M. Physio-genetic behavior of maize seedlings at water deficit conditions. Cerc. Agron. 2011, 2, 41-49. [CrossRef]

4. Hallauer, A.R.; Miranda, J.B. Quantitative Genetics in Maize Breeding, 2nd ed.; Iowa State University Press: Ames, IA, USA, 1988; pp. 86-89.

5. Sprague, G.F.; Tatum, L.A. General vs specific combining ability in single crosses of corn. Agron. J. 1942, 34, 923-932. [CrossRef]

6. Sleper, D.A.; Poehlman, J.M. Breeding Field Crops, 5th ed.; Blackwell Publishing: Hoboken, NJ, USA, 2006; pp. 119-185.

7. Novoselovic, D.; Baric, M.; Drezner, G.; Gunjaca, J.; Lalic, A. Quantitative inheritance of some wheat plant traits. Genet. Mol. Biol. 2004, 27, 92-98. [CrossRef] 
8. Mhike, X.; Lungu, D.M.; Vivek, B. Combining ability studies amongst AREX and CIMMYT maize (Zea mays L.) inbred lines under stress and non-stress conditions. Afr. J. Agric. Res. 2011, 6, 1952-1957.

9. Atif, I.A.; Awadalla, A.A.; Mutasim, M.K.; Atif, E.I.; Abdellatif, M.O. Combining ability and heterosis for yield and yield components in maize (Zea mays L.). AJBAS 2012, 6, 36-41.

10. Aminu, D.; Izge, A.U. Gene action and heterosis for yield and yield traits in maize (Zea mays L.) under drought conditions in Northern guinea and Sudan savannas of Boron State, Nigeria. PJAS 2013, 1, 17-23.

11. Meseka, S.K.; Menkir, A.; Ajala, S. Genetic analysis of performance of maize inbred lines under drought stress. J. Crop Improv. 2011, 25, 521-539. [CrossRef]

12. Aminu, D.; Muhammed, S.G.; Kabir, B.G. Estimates of combining ability and heterosis for yield and yield traits in maize population (Zea mays L.) under drought conditions in the Northern Guinea and Sudan savanna zones of Borno State, Nigeria. IJAIR 2014, 2, 824-830.

13. Umar, U.U.; Ado, S.G.; Aba, D.A.; Bugaje, S.M. Combining ability, gene action and heterosis in maize (Zea mays L.) under drought stress. Int. J. Agric. Innov. Res. 2014, 3, 953-958.

14. Rajesh, V.; Kumar, S.S.; Reddy, V.N.; Sankar, A.S. Combining Ability and Genetic Action Studies for Yield and Its Related Traits in Maize (Zea mays L.). Int. J. Curr. Microbiol. App. Sci. 2018, 7, 2645-2652. [CrossRef]

15. Naveed, M.; Ahsan, M.; Akram, H.M.; Aslam, M.; Ahmed, N. Genetic Effects Conferring Heat Tolerance in a Cross of Tolerant $\times$ Susceptible Maize (Zea mays L.) Inbred lines. Front. Plant Sci. 2016, 7, 729-740. [CrossRef] [PubMed]

16. Chen, J.; Xu, W.; Velten, J.; Xin, Z.; Stout, J. Characterization of maize inbred lines for drought and heat tolerance. J. Soil Water Conserv. 2012, 67, 354-364. [CrossRef]

17. Edmeades, G.O. Progress in Achieving and Delivering Drought Tolerance in Maize-An Update. Available online: https://isaaa.org/resources/publications/briefs/44/specialfeature/Progress\%20in\%20Achieving\% 20and\%20Delivering\%20Drought\%20Tolerance\%20in\%20Maize.pdf (accessed on 18 May 2015).

18. Pagano, E.; Maddonni, G.A. Intra-specific competition in maize: Early established hierarchies differ in plant growth and biomass partitioning to the ear around silking. Field Crops Res. 2007, 101, 306-320. [CrossRef]

19. Fischer, K.; Van den Berg, J.; Mutengwa, C. Is Bt maize effective in improving South African smallholder agriculture? S. Afr. J. Sci. 2015, 111, 1-2. [CrossRef]

20. Musila, R.N.; Diallo, A.O.; Makumbi, D.; Njoroge, K. Combining ability of early- maturing quality protein maize inbred lines adapted to Eastern Africa. Field Crops Res. 2010, 119, 231-237. [CrossRef]

21. The International Maize and Wheat Improvement Center (CIMMYT). Managing Trials and Reporting Data for CIMMYT International Maize Testing Program. Available online: http://www.cimmyt.org/ (accessed on 18 May 2015).

22. Hill, L.; Becker, H.C.; Tigerst, P.M.A. Quantitative and Ecological Aspects of Plant Breeding; Chapman and Hall: London, UK, 1998; pp. 67-83.

23. Krause, W.; Rodrigues, R.; Leal, N.R. Combining ability for agronomic traits in snap bean. Rev. Ciênc. Agron. 2012, 43, 522-531. [CrossRef]

24. Ejigu, Y.G.; Tongoona, P.B.; Ifie, B.E. General and specific combining ability studies of selected tropical white maize inbred lines for yield and yield related traits. Int. J. Agric. Sci. Res. 2017, 7, 381-396.

25. Shavrukov, Y.; Kurishbayev, A.; Jatayev, S.; Shvidchenko, V.; Zotova, L.; Koekemoer, F.; de Groot, S.; Soole, K.; Langridge, P. Early flowering as a drought escape mechanism in plants: How can it aid wheat production? Front Plant Sci. 2017, 8, 1950. [CrossRef]

26. Abbas, G.; Ahsan, M.; Saleem, M.; Ahmad, R. Inheritance study of different agronomic traits in mung $\times$ mash interspecific recombinant inbred lines. J. Anim. Plant Sci. 2016, 26, 149-155.

27. Abdel-Moneam, M.A.; Sultan, M.S.; Salama, S.M.G.; El Oraby, A.M. Evaluation of combining ability and heterosis for yield and its components traits of five maize inbreds under normal and stress nitrogen fertilization. Asian J. Crop Sci. 2014, 6, 142-149. [CrossRef]

28. Njeri, S.G.; Makumbi, D.; Warburton, M.L.; Jumbo, M.B.; Chemining'wa, G. Genetic analysis of tropical quality protein maize (Zea mays L.) germplasm. Euphytica 2017, 213, 261-280. [CrossRef]

29. Akbar, M.; Saleem, M.; Azhar, F.M.; Ashraf, M.Y.; Ahmad, R. Combining ability analysis in maize under normal and high temperature conditions. J. Agric. Res 2008, 46, 27-38.

30. Pfunde, C.N. Investigation into the Genetic Diversity, Physiology, Proteomics and Combining Ability of Quality Protein Maize Inbred Lines under Drought and Heat Stress. Ph.D. Thesis, University of Fort Hare, Alice, South Africa, 2016. 
31. Awata, L.A.O.; Ifie, B.; Tongoona, P.; Danquah, E.; Marchelo-Dragga, P.W. Common Mating Designs in Agricultural Research and Their Reliability in Estimation of Genetic Parameters. IOSR-JAVS 2018, 11, $16-36$. [CrossRef]

32. Makumbi, D. Phenotypic and Genotypic Characterization of White Maize Inbreds, Hybrids and Synthetics Under Stress and Non-Stress Environments. Ph.D. Thesis, Texas A\&M University, College Station, TX, USA, 2005.

33. Kaya, Y.; Atakisi, I.K. Combining ability analysis of some yield characters of sunflower (Helianthus annuus L.). Helia 2004, 27, 75-84.

34. Gevers, H.O. Patterns of Heterosis in South. African Maize Breeding; CIMMYT: Mexico City, Mexico, 1987; pp. 102-103.

(C) 2020 by the authors. Licensee MDPI, Basel, Switzerland. This article is an open access article distributed under the terms and conditions of the Creative Commons Attribution (CC BY) license (http://creativecommons.org/licenses/by/4.0/). 